\title{
Synthesis, structure and physical properties of a low dimensional compound
}

\author{
Manuela Ramos Silva ${ }^{1 *}$, Joana T. Coutinho ${ }^{2}$, Laura C. J. Pereira ${ }^{2}$, Pablo Martín-Ramos ${ }^{1,3}$ and João \\ C. Waerenborgh ${ }^{2}$ \\ ${ }^{1}$ CFisUC, Department of Physics, University of Coimbra, Rua Larga, P-3004-516 Coimbra, Portugal. \\ Phone: +351.239.410648; Fax: +351.239.829158; E-mail: manuela@pollux.fis.uc.pt \\ ${ }^{2}$ Centro de Ciências e Tecnologias Nucleares, Instituto Superior Técnico, Universidade de Lisboa, 2695- \\ 066 Bobadela LRS, Portugal \\ ${ }^{3}$ Higher Polytechnic School of Huesca, University of Zaragoza, Ctra. Cuarte s/n, 22071 Huesca, Spain.
}

\begin{abstract}
The crystal structure of $\left(\mu_{3}\right.$-охо)hexakis(cyanoacetato- $\left.\kappa \mathrm{O}, \mathrm{O}^{\prime}\right)$ (cyanoacetato$\kappa \mathrm{O}$ )diaquatriiron(III) cyanoacetic acid shows the formation of trinuclear complexes in a hydrogen-bond network that bonds all the molecules in a 3D arrangement. For this complex, within whose clusters the whole magnetic interaction takes place, ${ }^{57} \mathrm{Fe}$ Mössbauer spectroscopy shows that the Fe cations are in the $\mathrm{S}=5 / 2$ state in the temperature range $2-295 \mathrm{~K}$. The asymmetric broadening of the absorption peaks below $80 \mathrm{~K}$ is consistent with strong antiferromagnetic interactions between the metal spins. The magnetization measurements also show the antiferromagnetic character of the spin ensemble and an $S_{\mathrm{T}}=1 / 2$ magnetic ground state typical of triangular systems with similar $J$ between Fe-Fe pairs.
\end{abstract}

Keywords: AFM interaction; cyanoacetate; low dimensional compound; trinuclear Fe(III) complex.

\section{Introduction}

Miniaturization is a key technological aspect and magnets of molecular origin may act as nanosized magnets with self-assembling properties. Some of these self-assembled complexes, containing a small number of interacting magnetic moments, have magnetic ground states and originate hysteresis effects and metastable magnetic phases. Others exhibit pronounced frustration effects, but all provide ideal opportunities to investigate low-dimensional magnetism [1].

Involved in the molecular magnets family are the trinuclear oxo-centered, iron carboxylate complexes that have been widely investigated [2]. It has been established that in both mixedvalence $\left(\mathrm{Fe}^{\mathrm{II}} / \mathrm{Fe}^{\mathrm{III}}\right)$ and $\mathrm{Fe}^{\mathrm{III}}$ compounds, the metal ions in the tri-iron oxo-centred units are antiferromagnetically coupled and spin frustration occurs due to the triangular geometry of the $\mathrm{Fe}_{3} \mathrm{O}$ core. An equilateral triangular geometry is unstable and a lower energy may be obtained by lifting the degeneracy of the ground state in what has been called a "magnetic Jahn-Teller effect" [2]. In several crystallographic studies of carboxylate complexes of oxo-centred trinuclear iron compounds with orthorhombic or monoclinic structures, a rather close non-crystallographic threefold symmetry of the complex was found, and in a few reported crystal structures, there is an exact crystallographically imposed $C_{3}$ or even higher $D_{3 h}$ symmetry [3,4].

In this type of triangular-bridged complexes, the metal-metal distances are large enough to preclude direct metal-metal interaction and so it is an indirect exchange mechanism, via both the oxide ion and the carboxylate groups, that is responsible for the antiferromagnetic coupling between the spins. Therefore these simple polynuclear systems allow a critical investigation of the theory of the exchange interaction. 


\section{Experimental section}

\subsection{Synthesis}

The reagents used were commercially available and used without further purification. $1 \mathrm{mmol}$ of $\mathrm{FeCl}_{3}$ and $2 \mathrm{mmol}$ of cyanoacetic acid were dissolved in $30 \mathrm{ml}$ of water, following the method described in [5]. The solution was stirred at room temperature and left undisturbed by several days after which prismatic crystals formed.

\section{2. $X$-ray diffraction}

The single crystals were carefully selected under an optical microscope and glued into a thin glass fibre. Diffraction data were recorded in a Bruker Apex II diffractometer with Mo-K $\alpha$ radiation $(\lambda=0.71073 \AA$ ) at 293(2) K. Data processing was accomplished with use of the program SAINT; an empirical absorption correction based on symmetry equivalent reflections was applied using the SADABS program [6]. The structures were solved with direct methods and refined with full-matrix least-squares (SHELX-97) [7]. All non-hydrogen atoms were refined anisotropically by least-squares on $F^{2}$. Hydrogen atoms on the acidic ligands were generated by the riding mode. Coordinating water hydrogen atoms and the carboxylic $\mathrm{H}$ atom were located in a Fourier synthesis difference.

Crystal data as well as the details of data collection and refinement are summarized in Table 1. Selected bond distances are listed in Table 2 and Table 3

\subsection{Magnetic Measurements}

The magnetic susceptibility under several magnetic fields was measured with a S700X SQUID magnetometer (Cryogenic Ltd) in the temperature range 2-300 $\mathrm{K}$ and assuming a diamagnetic contribution of $2.98 \times 10^{-4} \mathrm{emu} / \mathrm{mol}$ (estimated from tabulated Pascal constants).

Mössbauer spectra were collected between 295 and $2.0 \mathrm{~K}$ in transmission mode using the triangular velocity reference signal of a conventional constant-acceleration spectrometer (MR360 drive unit, MA260 transducer from Wissenschaftliche Elektronik GmbH, Starnberg, Germany) and a $25 \mathrm{mCi}^{57} \mathrm{Co}$ source in a Rh matrix. The velocity scale was calibrated using $\alpha$-Fe foil. Isomer shifts, $\delta$, are given relative to this standard at room temperature. The absorber was obtained by packing the powdered sample $\left(5 \mathrm{mg}\right.$ of natural $\mathrm{Fe} / \mathrm{cm}^{2}$ ) into a perspex holder. Low-temperature spectra were collected in a bath cryostat with the sample immersed in liquid He for measurements at $\leq 4.2 \mathrm{~K}$ and in He exchange gas for temperatures $>4.2 \mathrm{~K}$. The source was always kept at 295 K. Each spectrum was measured during approximately 24 hours and the average number of baseline counts are $4 \times 10^{5}$. This means standard deviations of $0.2 \%$ of the number of counts [8]. The folded spectra (consisting of 256 channels) were fitted to Lorentzian lines using a non-linear least-squares method described in detail in ref. [9]. The computer program initially designed for a main frame computer was adapted to real time processing in personal computers but no changes were made to the refinement algorithm [10].

\section{Results and Discussion}

\subsection{Structural properties}

$\left(\mu_{3}\right.$-oxo)hexakis(cyanoacetato- $\left.\kappa \mathrm{O}, \mathrm{O}^{\prime}\right)($ cyanoacetato- $\kappa \mathrm{O})$ diaquatriiron(III) cyanoacetic acid crystallizes in a monoclinic $\mathrm{P} 2_{1} / \mathrm{m}$ space group. The crystal content consists of trinuclear $\left[\mathrm{Fe}_{3} \mathrm{O}\left(\mathrm{CNCH}_{2} \mathrm{COO}\right)_{7}\left(\mathrm{H}_{2} \mathrm{O}\right)_{2}\right]$ complexes and neutral $\left[\mathrm{CNCH}_{2} \mathrm{COOH}\right]$ acid molecules, see Figure 1 . The Fe(III) ions occupy 3 crystallographic independent positions. The central fragment of the complex cation is a planar $\left[\mathrm{Fe}_{3} \mathrm{O}\right]$ core. The three iron atoms are linked by the $\mu_{3}$-oxygen atom and lie at the vertices of a nearly regular triangle, the $\mathrm{Fe}-\mathrm{O}$ distances range from 1.896(2) to 1.936(2) $\AA$. The sum of the bond angles at $\mathrm{O} 1$ atom is $360.0(3)^{\circ}$. 
Table 1. Crystal data and structure refinement parameters.

\begin{tabular}{cc} 
Empirical formula & $\mathrm{C}_{24} \mathrm{H}_{21} \mathrm{Fe}_{3} \mathrm{~N}_{8} \mathrm{O}_{19}$ \\
Formula weight & 893.04 \\
Temperature $(\mathrm{K})$ & $293(2)$ \\
Wavelength $(\AA)$ & 0.71073 \\
Crystal system & Monoclinic \\
Space group & $\mathrm{P} 2{ }_{1} / \mathrm{m}$ \\
$a(\AA)$ & $9.6330(4)$ \\
$b(\AA)$ & $14.3918(5)$ \\
$c(\AA)$ & $12.9220(5)$ \\
$\alpha\left(^{\circ}\right)$ & 90 \\
$\beta\left(^{\circ}\right)$ & $109.144(2)$ \\
$\gamma\left({ }^{\circ}\right)$ & 90 \\
Volume $\left(\AA^{3}\right)$ & $1692.38(11)$ \\
$Z$ & 2 \\
Calculated density (g/cm $\left.{ }^{3}\right)$ & 1.752 \\
Absorption coefficient $\left(\mathrm{mm}^{-1}\right)$ & 1.363 \\
$F(000)$ & 902 \\
$\theta$ range for data collection $\left(^{\circ}\right)$ & $2.19-25.81$ \\
Index ranges & $-17<k<17 ;-15<l<15$ \\
Reflections collected/unique & $30731 / 3385$ \\
Completeness to $\theta$ max & $99.8 \%$ \\
Refinement method & Full matrix LS on $\mathrm{F}^{2}$ \\
Data/restraints/parameters & $3385 / 0 / 284$ \\
Goodness-of-fit on $F^{2}$ & 0.999 \\
Final R indices $[I>2 \sigma(I)]$ & $0.0262 / 0.0590$ \\
$\mathrm{R}$ indices (all data) & $0.0371 / 0.0638$ \\
Largest diff. peak and hole $\left(\mathrm{e} \AA^{-3}\right)$ & -0.3420 .327 \\
\hline
\end{tabular}

Six cyanoacetate ions act as bidentate syn-syn bridges linking the iron atoms in pairs into the cluster and forming an equatorial plane of 4 oxygen atoms. The axial positions are occupied by the central $\mathrm{O}$ atom and either a water $\mathrm{O}$ atom for $\mathrm{Fe} 1$ and $\mathrm{Fe} 3$ or a cyanoacetonate $\mathrm{O}$ atom for $\mathrm{Fe} 2$.

The coordination polyhedron of the Fe atoms is slightly distorted from ideal octahedral geometry, with the iron atoms lying 0.0421(4), 0.0776(4) and 0.02072(4) $\AA$ (for Fe1, Fe2 and $\mathrm{Fe} 3$, respectively) above the oxygen equatorial plane towards the central oxygen ion.

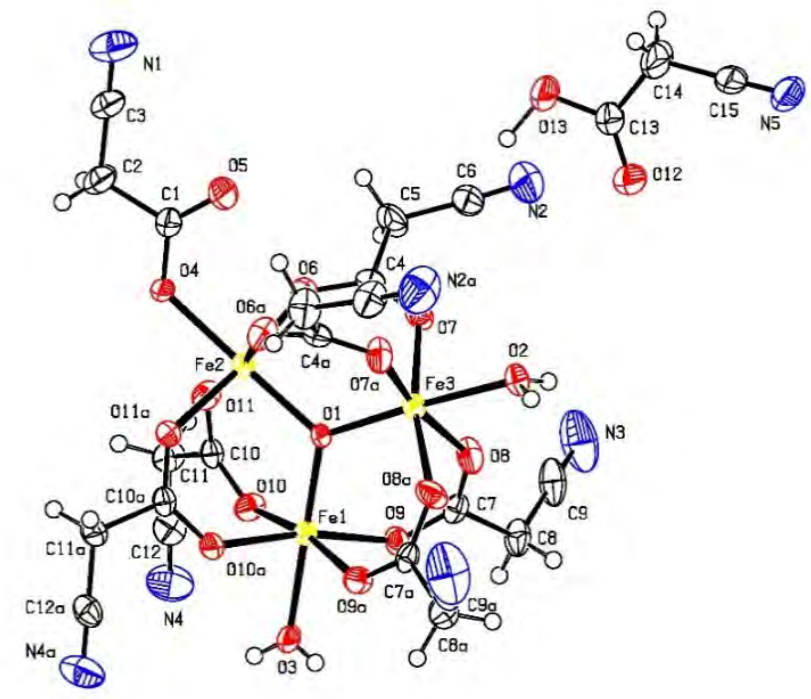

Figure 1. ORTEP diagram of the Fe(III) compound drawn at the 50\% probability level. 
The iron-iron interatomic distance, $3.3 \AA$, is sufficiently long to preclude direct metal-metal bonding. As a first approximation, the idealized symmetry of the inner cluster may be considered as $\mathrm{D}_{3 \mathrm{~h}}$.

Within the cyanoacetic ions, the $\mathrm{C}-\mathrm{O}$ distances are approximately equal, as expected in deprotonated carboxylic groups, Table 2. The cyanoacetate ions have different conformations; some are nearly eclipsed when viewed along the C1-C2 single bond, the other ( $\mu_{2}$-cyanoaetonates) are more twisted with the torsion angles differing from 8 to $53^{\circ}$ from the ideal $0^{\circ}$ of a total eclipsed conformation.

Table 2. Selected Fe-O and C-O bond lengths $(\AA)$.

\begin{tabular}{cccc}
\hline Bond & Length & Bond & Length \\
\hline Fe1-O1 & $1.8967(19)$ & O4-C1 & $1.295(4)$ \\
Fe1-O3 & $2.059(3)$ & O5-C1 & $1.203(4)$ \\
Fe1-O9 & $2.0246(14)$ & O6-C4 & $1.244(3)$ \\
Fe1-O10 & $2.0062(14)$ & O7-C4 & $1.246(3)$ \\
Fe2-O1 & $1.9363(19)$ & O8-C7 & $1.239(3)$ \\
Fe2-O4 & $2.033(2)$ & O9-C7 & $1.243(2)$ \\
Fe2-O6 & $2.0050(15)$ & O10-C10 & $1.248(2)$ \\
Fe2-O11 & $2.0272(14)$ & O11-C10 & $1.246(2)$ \\
Fe3-O1 & $1.8986(19)$ & O12-C13 & $1.194(4)$ \\
Fe3-O2 & $2.068(2)$ & O13-C13 & $1.303(4)$ \\
Fe3-O7 & $1.9997(15)$ & & \\
Fe3-O8 & $2.0179(15)$ & & \\
\hline
\end{tabular}

In the asymmetric unit, there is an uncoordinated neutral cyanoacetic acid molecule that is $\mathrm{H}$ bonded to two distinct clusters (Figure 2, Table 3). The H-atoms of the water molecules are also involved in the hydrogen-bond network that bonds all the molecules in a 3D arrangement.

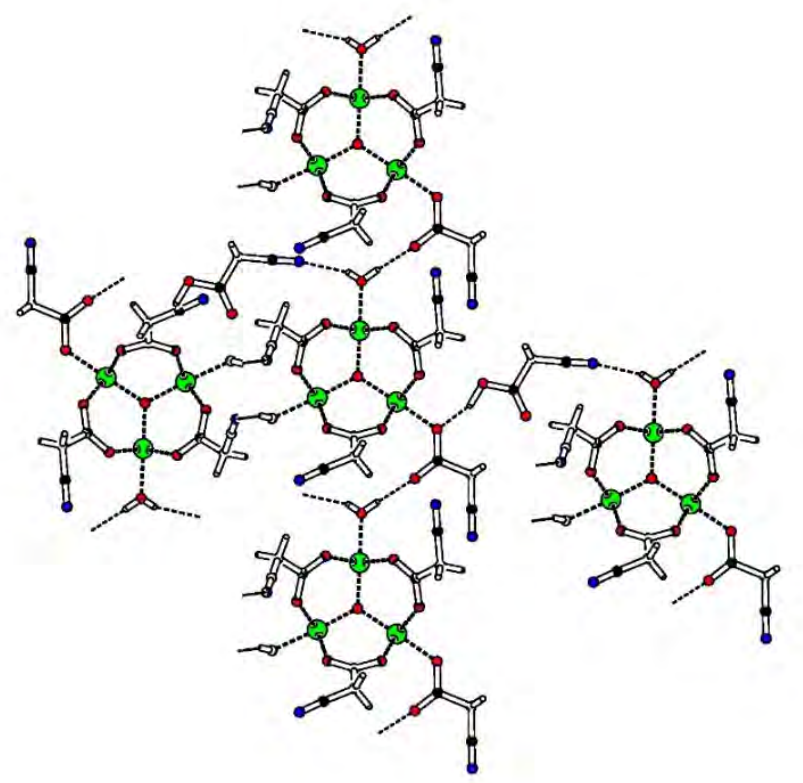

Figure 2. H-bond network depicted as dashed lines. 
Table 3. H-bond geometry in $(\AA)$ and $\left({ }^{\circ}\right)$.

\begin{tabular}{ccccc}
\hline D-H...A & D-H & H...A & D...A & angle \\
\hline O2-H2A...N3 & $0.76(3)$ & $2.06(3)$ & $2.814(3)$ & $168(3)$ \\
O3-H3A...N5 ${ }^{i i}$ & $0.64(4)$ & $2.12(4)$ & $2.729(5)$ & $159(5)$ \\
O3-H3B...O5 & $0.78(5)$ & $1.87(5)$ & $2.648(4)$ & $177(5)$ \\
O13-H13...O4 & $1.04(7)$ & $1.69(7)$ & $2.686(3)$ & $157(6)$ \\
\hline
\end{tabular}

i: $-1-\mathrm{x},-\mathrm{y},-1-\mathrm{z} ;$ ii: $\mathrm{x}, \mathrm{y},-1+\mathrm{z}$; iii: 1+x,y,z.

\subsection{Magnetic properties}

The magnetic properties of the trinuclear compound were measured on polycrystalline samples and the phase purity was confirmed via powder XRD patterns (not shown).

The temperature dependence of the paramagnetic susceptibility measured in the range 2-300 $\mathrm{K}$ at 1 Tesla is shown in Figure 3 both as $\chi$ and as $\chi \mathrm{T}$. At room temperature, the $\chi \mathrm{T}$ value is $\sim 4$ $\mathrm{emu} \cdot \mathrm{K} / \mathrm{mol}$, well below that of the spin-only value expected for three $\mathrm{Fe}(\mathrm{III})$ ions with $\mathrm{S}=5 / 2$ and $\mathrm{g}=2(\chi \mathrm{T}=13.12 \mathrm{emu} \cdot \mathrm{K} / \mathrm{mol})$. While cooling, a strong decrease of $\chi \mathrm{T}$ down to $0.31 \mathrm{emu} \cdot \mathrm{K} / \mathrm{mol}$ at $3.9 \mathrm{~K}$ is observed. This is in agreement with previous studies on other similar trinuclear Fe(III) oxo-centered complexes where the same type of behavior has been reported [4,11-18].

In the high-temperature range, the magnetic susceptibility shows a Curie-Weiss behavior with a large negative Weiss temperature, $\theta=-429 \mathrm{~K}$, qualitatively attributed to the presence of strong antiferromagnetic, AFM, coupling between spins.

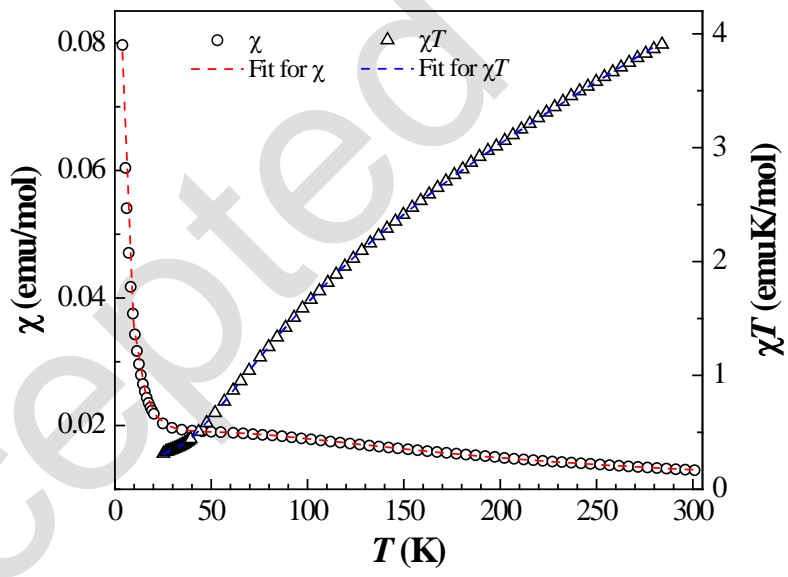

Figure 3. Temperature dependence of the magnetic susceptibility, $\chi$, and $\chi \mathrm{T}$. Dashed lines represent the fit according to the text.

The existence of a quasi-plateau below $20 \mathrm{~K}$ in the $\chi \mathrm{T}$ curve, at ca $0.38 \mathrm{emu} \cdot \mathrm{K} / \mathrm{mol}$, suggests the stabilization of a magnetically isolated low lying spin state, $S_{T}=1 / 2$, as expected for triangular systems with similar $J$ between Fe-Fe pairs $[1,16]$. Finally, the residual value is probably due to a small fraction of a paramagnetic impurity with a Curie tail, as discussed below.

According to structural data, $\mathrm{Fe}_{3} \mathrm{O}\left(\mathrm{CNCH}_{2} \mathrm{COO}\right)_{7}\left(\mathrm{H}_{2} \mathrm{O}\right)_{2}$ may be considered as an assembly of quasi-isolated triangular units of $\mathrm{Fe}(\mathrm{III})$ with $\mathrm{S}=5 / 2$ spins [19]. The $\mathrm{Fe}(1)-\mathrm{Fe}(2), \mathrm{Fe}(2)-\mathrm{Fe}(3)$ and $\mathrm{Fe}(1)-\mathrm{Fe}(3)$ distances at room temperature (3.306, 3.333, $3.288 \AA$, respectively) differ by less than $2 \%$. However, the magnetic behavior of this compound could not be analyzed assuming that the triangular units of $\mathrm{Fe}(\mathrm{III})$ are equilateral $\left(\mathrm{D}_{3 \mathrm{~h}}\right.$ point group) and that the exchange interactions between all Fe-Fe pairs are equal $J_{12}=J_{23}=J_{13}=J$ as in the case of other trinuclear Fe(III) complexes $[4,19,20]$ where the three Fe-Fe interatomic distances are even closer to each other 
than in this compound. A $\mathrm{C}_{2 \mathrm{v}}$ group symmetry (isosceles triangle) was therefore considered, assuming $J_{12}=J_{13}=J$ corresponding to the 3.306(2) and 3.288(2) $\AA$ distances, and a weaker $J_{23}$ corresponding to the 3.333(2) $\AA$ distance. For this symmetry [16,18], the Hamiltonian of the Heisenberg-Dirac-Van Vleck model for three coupled $s_{i}=5 / 2$ spins (strictly localized oxidation states, high-spin configurations and negligible orbital angular moments) is given by:

$$
\vec{H}=-2 J\left[\left(\vec{s}_{1} \vec{s}_{2}\right)+\left(\vec{s}_{1} \vec{s}_{3}\right)\right]-2 J_{23}\left(\vec{s}_{2} \vec{s}_{3}\right)
$$

The temperature dependence of the magnetic susceptibility data was analyzed with the expression given in reference [18] and taking into account the eight lowest energy levels.

This fitting model gives a good reproduction of the experimental data $\left(\chi^{2}=4 \times 10^{-5}\right)$ as shown in Figure 3 with $\mathrm{g}=2, J=-45.4 \mathrm{~K}\left(-32 \mathrm{~cm}^{-1}\right), J_{23}=-39.8 \mathrm{~K}\left(-28 \mathrm{~cm}^{-1}\right)$, and less than $1 \%$ paramagnetic impurities. Although different, the $J$ and $J_{23}$ values are close, which is consistent with the small difference between the largest Fe-Fe distance and the shorter ones. The $J$ and $J_{23}$ values are also within the range found for most trinuclear Fe(III) oxo-centered complexes [4,11,13,17].

A calculation of the energy levels of the three interacting spins following the Kambe vector coupling approach [2] shows a splitting of $64 \mathrm{~cm}^{-1}$ between the $S_{\mathrm{T}}=1 / 2$ spin ground state and the lowest excited state with $S_{T}=3 / 2$ (Figure 4). The temperature dependence of the population of some of these states is also plotted; at room temperature the states with higher total spin are scarcely populated.
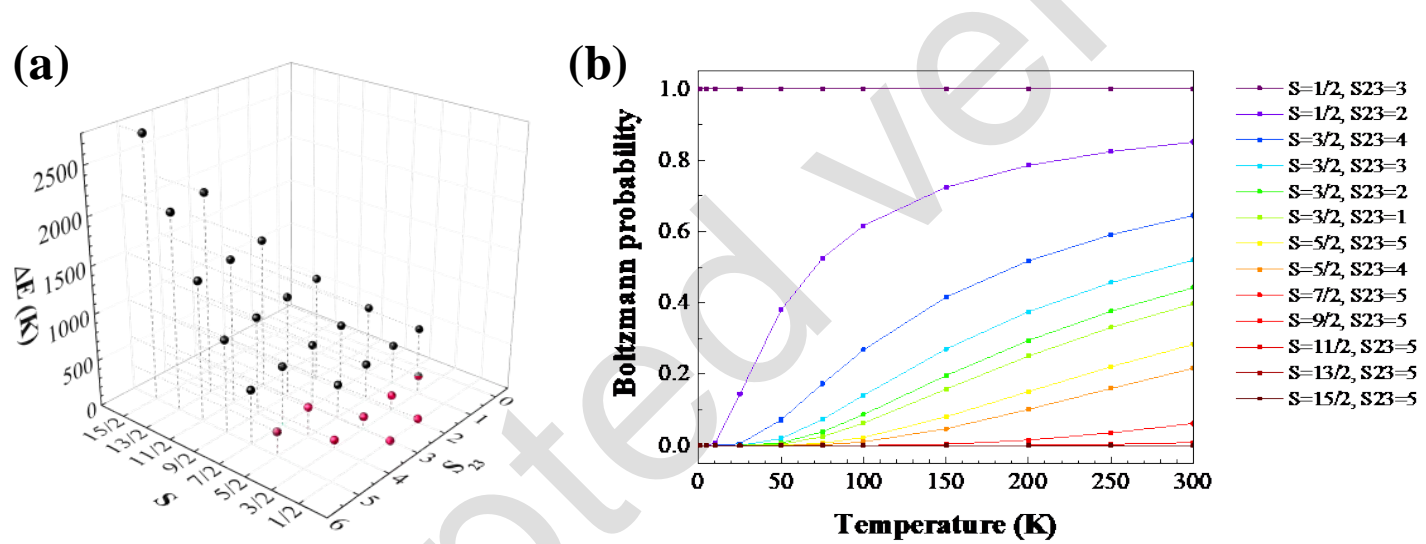

Figure 4. Energy levels (left) and temperature dependence of the population of some selected levels (not normalized) (right).

The Mössbauer spectra (Figure 5) consist of two absorption peaks in the temperature range 2$295 \mathrm{~K}$. In the range 295-50 K the spectra may be fitted by a single, slightly asymmetric, quadrupole doublet. The occurrence of a single doublet is in fair agreement with the similarity of the first coordination spheres of the Fe cations in the three different crystallographic sites. The estimated $\delta$ relative to metallic Fe at $295 \mathrm{~K}$ increases from $0.42 \mathrm{~mm} / \mathrm{s}$ at room temperature up to $0.54 \mathrm{~mm} / \mathrm{s}$ at $50 \mathrm{~K}$ (Table 4) as expected from the second order Doppler shift. The estimated line widths for each absorption peak $(0.32,0.34 \mathrm{~mm} / \mathrm{s})$ are similar at 295 and $145 \mathrm{~K}$. At $80 \mathrm{~K}$ they are significantly larger $(0.39,0.40 \mathrm{~mm} / \mathrm{s})$ and further increase as the temperature decreases $(0.44$, $0.45 \mathrm{~mm} / \mathrm{s}$ at $50 \mathrm{~K}$ and $0.79,0.70 \mathrm{~mm} / \mathrm{s}$ at $4 \mathrm{~K}$ ).

The $\delta$ values are characteristic of $\mathrm{S}=5 / 2 \mathrm{Fe}(\mathrm{III})$ ion in an octahedral oxygen environment [8] and similar to those reported for $\mathrm{Fe}(\mathrm{III})$ in the $\left[\mathrm{Fe}_{3} \mathrm{O}\left(\mathrm{CNCH}_{2} \mathrm{COO}\right)_{6}\left(\mathrm{H}_{2} \mathrm{O}\right)_{3}\right] \cdot\left[\mathrm{NO}_{3}\right] \cdot 5 \mathrm{H}_{2} \mathrm{O}$ compound [11] as well as in other $\mathrm{Fe}_{3}\left(\mu_{3}-\mathrm{O}\right)$ trinuclear complexes [8,12,13,15-17]. A non-zero quadrupole splitting, $\Delta \mathrm{E}_{\mathrm{Q}}$, is observed due to the non-cubic charge distribution symmetry around the Fe cations. $\Delta \mathrm{E}_{\mathrm{Q}} \sim 0.67 \mathrm{~mm} / \mathrm{s}$, remains approximately constant within experimental error in the investigated temperature range in agreement with an $S=5 / 2$ state where no electronic contribution to the electric field gradient is expected. 
Table 4. Estimated parameters for the Mössbauer spectra taken at different temperatures

\begin{tabular}{cccccc}
\hline $\mathrm{T}$ & $\delta$ & $\Delta \mathrm{E}_{\mathrm{Q}}$ & $\Gamma$ & $\Gamma_{\mathrm{r}}$ & $\mathrm{A}_{\mathrm{r}}$ \\
\hline $295 \mathrm{~K}$ & 0.42 & 0.64 & 0.33 & 1.07 & 1.00 \\
$145 \mathrm{~K}$ & 0.49 & 0.61 & 0.32 & 1.07 & 1.02 \\
$80 \mathrm{~K}$ & 0.53 & 0.66 & 0.39 & 1.03 & 0.99 \\
$50 \mathrm{~K}$ & 0.54 & 0.67 & 0.44 & 1.02 & 0.99 \\
$4 \mathrm{~K}$ & 0.53 & 0.67 & 0.79 & 0.89 & 1.02 \\
$2 \mathrm{~K}$ & 0.53 & 0.67 & 0.79 & 0.91 & 1.02 \\
\hline
\end{tabular}

$\delta$ : isomer shift relative to metallic $\alpha$-Fe at $295 \mathrm{~K} ; \Delta \mathrm{E}_{\mathrm{Q}}$ : quadrupole splitting; $\Gamma$ : full width at half maximum; $\Gamma_{\mathrm{r}}, \mathrm{A}_{\mathrm{r}}$ ratios between the widths and relative areas, respectively, of the low and high velocity peaks. Estimated errors are $\leq 0.02 \mathrm{~mm} / \mathrm{s}$ for $\delta, \Delta \mathrm{E}_{\mathrm{Q}}$ and $\Gamma,<2 \%$ for $\Gamma_{\mathrm{r}}$ and $\mathrm{A}_{\mathrm{r}}$.

The asymmetry of the absorption peaks observed below $50 \mathrm{~K}$ is not attributed to GoldanskiiKaryagin effect since the estimated relative areas of both peaks are the same within experimental error [21]. The sudden increase of the peak widths observed below $80 \mathrm{~K}$ may rather be explained by a decrease of the relaxation frequency of the direction of the Fe(III) magnetic moments due to the presence of strong AFM interactions [8,15,17]. The relaxation frequency, however, is not low enough to allow the observation of magnetic splittings which implies that no long range magnetic correlations are established. Fitting the 4 and $2 \mathrm{~K}$ spectra with a distribution of quadrupole splittings the estimated average IS is $0.53 \mathrm{~mm} / \mathrm{s}$, the same, within experimental error, as the IS of the doublet observed at $50 \mathrm{~K}$ and confirming that all the Fe cations remain in the $S=5 / 2$ state. 


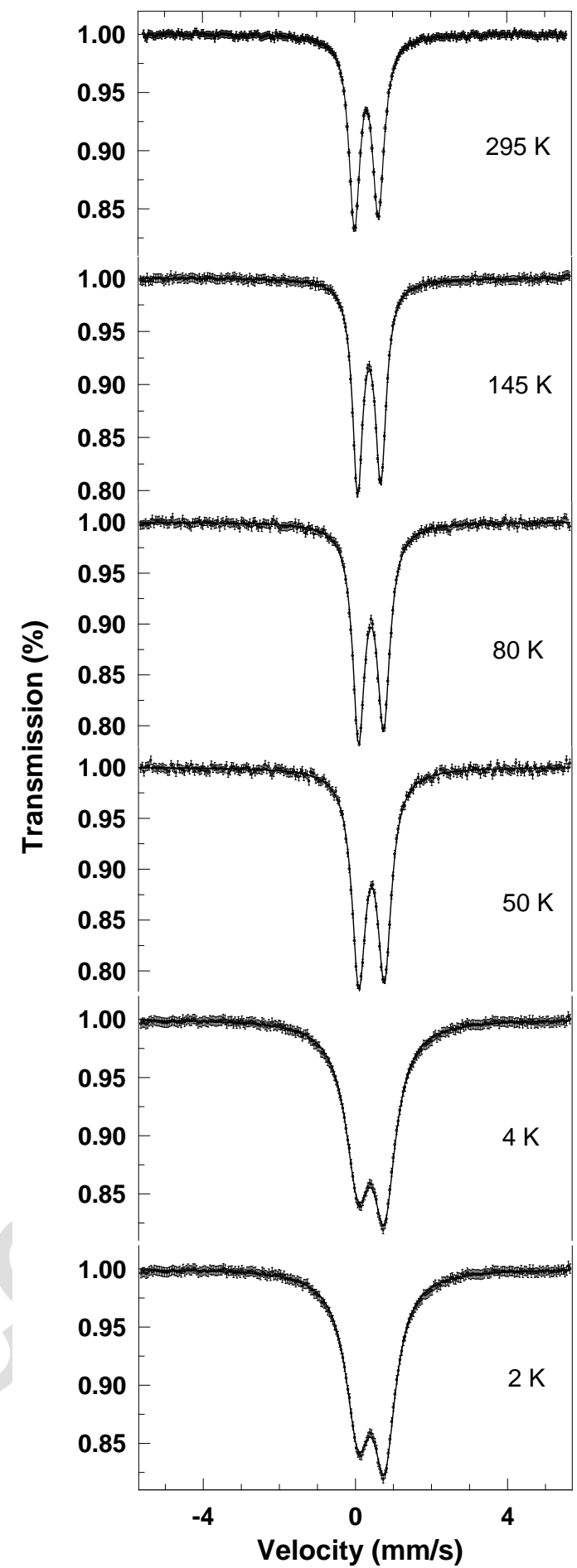

Figure 5. Mössbauer spectra of the trinuclear Fe(III) complex taken at different temperatures. The lines over the experimental points are the calculated quadrupole doublets. 


\section{Conclusions}

In an attempt to explore the superexchange ability of the cyanoacetic acid we have obtained a trinuclear iron complex, which contains the "iron basic carboxylate" core.

Mossbauer spectroscopy applied to the trinuclear iron complex consists of two absorption peaks, and reveals that all the Fe cations are in the high spin, $S=5 / 2$, state.

The magnetic properties of this compound are satisfactorily described by an isosceles two- $J$ model. The exchange parameters $\left(J=-45.4 \mathrm{~K}, J_{23}=-39.8 \mathrm{~K}\right)$ are close, in agreement with the small difference between the largest and the shorter Fe-Fe interatomic distances. An $S_{T}=1 / 2$ ground spin state, with an antiferromagnetic interaction between the spins is obtained. An antiferromagnetic interaction between spins in a nearly isosceles triangular arrangement makes this compound another example of a geometrically frustrated material.

\section{Acknowledgements}

P.M.R. would like to gratefully acknowledge the financial support of CAI-Ibercaja scholarship program. $\mathrm{C}^{2} \mathrm{TN} / \mathrm{IST}$ authors gratefully acknowledge the support of the Portuguese Foundation for Science and Technology (FCT, Portugal), through contract UID/Multi/04349/2013.

\section{References}

[1] O. Kahn, Molecular magnetism, VCH Publishers, Inc., 1993, 393 pp.

[2] R.D. Cannon, R.P. White, Chemical and Physical Properties of Triangular Bridged Metal Complexes, in: S.J. Lippard (Ed.) Prog. Inorg. Chem., John Wiley \& Sons, Inc., Hoboken, NJ, USA, 1988, pp. 195-298.

[3] P.A. Angaridis, P. Baran, R. Boča, F. Cervantes-Lee, W. Haase, G. Mezei, R.G. Raptis, R. Werner, Synthesis and Structural Characterization of Trinuclear CuII-Pyrazolato Complexes Containing $\mu_{3}-\mathrm{OH}, \mu_{3}-\mathrm{O}$, and $\mu_{3}-\mathrm{Cl}$ Ligands. Magnetic Susceptibility Study of $[\mathrm{PPN}]_{2}\left[\left(\mu_{3}-\mathrm{O}\right) \mathrm{Cu}_{3}(\mu-\mathrm{pz})_{3} \mathrm{Cl}_{3}\right]$, Inorg. Chem., 41 (2002) 2219-2228.

[4] K.S. Gavrilenko, A. Addison, L. Thompson, V.V. Pavlishchuk, Magnetic Characteristics of Trinuclear Complexes $\left[\mathrm{M}_{3} \mathrm{O}\left(\mathrm{CH}_{3} \mathrm{COO}\right)_{6}(\mathrm{pz})_{3}\right]^{+}(\mathrm{M}=\mathrm{Fe}, \mathrm{Cr}$; pz $=$ Pyrazine $)$, Theor. Exp. Chem., 40 (2004) 214-219.

[5] M. Ramos Silva, J.N.J. Nogueira, P.A.O.C. Silva, C. Yuste-Vivas, L.C.J. Pereira, J.C. Waerenborgh, Oxo-Bridged Trinuclear Fe(III) Complexes: Structural and Magnetic Properties, Solid State Phenomena, 194 (2012) 162-170.

[6] G. Sheldrick, SADABS, in, University of Göttingen, Göttingen, Germany, 1996.

[7] G.M. Sheldrick, A short history of SHELX, Acta Crystallogr. Sect. A: Found. Crystallogr., 64 (2007) 112-122.

[8] N.N. Greenwood, T.C. Gibb, Mössbauer spectroscopy, Chapman and Hall, London,, 1971, xii, 659 p. pp.

[9] A.J. Stone, Least squares fitting of Mössbauer spectra, appendix to Bancroft GM, Maddock AG, Ong WK, Prince RH, Stone AJ 1967 J. Chem. Soc. A 1966, J. Chem. Soc. A, (1967) 1966-1971.

[10] J.C. Waerenborgh, D.P. Rojas, N.P. Vyshatko, A.L. Shaula, V.V. Kharton, I.P. Marozau, E.N. Naumovich, $\mathrm{Fe}^{4+}$ formation in brownmillerite $\mathrm{CaAl}_{0.5} \mathrm{Fe}_{0.5} \mathrm{O}_{2.5+\delta}$, Mater. Lett., 57 (2003) 4388-4393.

[11] S. Shova, I. Kadelnik, F. Zhovmir, I. Bulgak, V. Bel'skii, K. Turte, Synthesis and Study of a Trinuclear Complex of Iron(III) with Cyanoacetic Acid, Russian Journal of Coordination Chemistry C/C Koordinatsionnaia Khimiia, 23 (1997) 629-635.

[12] L.N. Mulay, G.H. Ziegenfuss, Exchange interactions in isolated trinuclear clusters of $\mathrm{Fe}^{3+}$ : magnetic and mössbauer studies, AIP Conf. Proc., 24 (1975) 213-214.

[13] C.P. Raptopoulou, V. Tangoulis, V. Psycharis, Synthesis and Structural, Spectroscopic, and Magnetic Characterization of $\left(\mathrm{NH}_{4}\right)\left[\mathrm{Fe}_{3}\left(\mu_{3}-\mathrm{OH}\right)\left(\mathrm{H}_{2} \mathrm{~L}\right)_{3}(\mathrm{HL})_{3}\right]\left(\mathrm{H}_{3} \mathrm{~L}=\right.$ Orotic Acid) 
Presenting Two Novel Metal-Binding Modes of the Orotate Ligand: The Case of a SpinFrustrated System, Inorg. Chem., 39 (2000) 4452-4459.

[14] C. Dendrinou-Samara, S. Katsamakas, C. Raptopoulou, A. Terzis, V. Tangoulis, D.P. Kessissoglou, Interaction of Fe(III) with herbicide-carboxylato ligands - Di-, tri- and tetranuclear compounds: Structure and magnetic behavior, Polyhedron, 26 (2007) 763-772.

[15] A.K. Boudalis, Y. Sanakis, C.P. Raptopoulou, A. Terzis, J.-P. Tuchagues, S.P. Perlepes, A trinuclear cluster containing the $\left\{\mathrm{Fe}_{3}\left(\mu_{3}-\mathrm{O}\right)\right\}^{7+}$ core: Structural, magnetic and spectroscopic (IR, Mössbauer, EPR) studies, Polyhedron, 24 (2005) 1540-1548.

[16] M. François, M.I. Saleh, P. Rabu, M. Souhassou, B. Malaman, J. Steinmetz, Structural transition at $225 \mathrm{~K}$ of the trinuclear $\mathrm{Fe}(\mathrm{III})$ heptanoate $\left[\mathrm{Fe}_{3} \mathrm{O}\left(\mathrm{O}_{2} \mathrm{CC}_{6} \mathrm{H}_{13}\right)_{6}\left(\mathrm{H}_{2} \mathrm{O}\right)_{3}\right] \mathrm{NO}_{3}$, Solid State Sciences, 7 (2005) 1236-1246.

[17] D. Piñero, P. Baran, R. Boca, R. Herchel, M. Klein, R.G. Raptis, F. Renz, Y. Sanakis, A Pyrazolate-Supported $\mathrm{Fe}_{3}\left(\mu_{3}-\mathrm{O}\right)$ Core: Structural, Spectroscopic, Electrochemical, and Magnetic Study, Inorg. Chem., 46 (2007) 10981-10989.

[18] K.I. Turta, A.O. Solonenco, I.I. Bulgak, F.K. Jovmir, M. Rosenberg, P. Stelmaszyk, G. Filoti, The magnetic properties of trinuclear Fe(III) substituted carboxylate clusters, J. Radioanal. Nucl. Chem., 190 (1995) 347-355.

[19] M.-L. Tong, X.-M. Chen, Z.-M. Sun, D. Hendrickson, Synthesis, crystal structure and magnetic properties of triaquahexakis $\left(\mu_{2}\right.$-betaine $)\left(\mu_{3}\right.$-oxo)triiron(III) perchlorate heptahydrate, Transition Met. Chem., 26 (2001) 195-197.

[20] F. Degang, W. Guoxiong, T. Wenxia, Y. Kaibei, The structure and magnetic properties of $\mu_{3}$-oxotriiron(III) complex $\left[\mathrm{Fe}_{3} \mathrm{O}(\mathrm{OBZ})_{6}\left(\mathrm{CH}_{3} \mathrm{OH}\right)_{3}\right]\left(\mathrm{NO}_{3}\right)\left(\mathrm{CH}_{3} \mathrm{OH}\right)_{2}(\mathrm{HOBZ}=$ benzoic acid), Polyhedron, 12 (1993) 2459-2463.

[21] V.I. Gol'danski1̌, R.H. Herber, Fundamentals of Gamma-Resonance spectroscopy, in: V.I. Gol'danskiı̈, R.H. Herber (Eds.) Chemical applications of Mössbauer spectroscopy, Academic Press, New York, 1968, pp. 701. 